\title{
CONSULTORIA COLABORATIVA COMO ESTRATÉGIA DE FORMAÇÃO CONTINUADA PARA PROFESSORES QUE ATUAM COM ESTUDANTES COM DEFICIÊNCIA INTELECTUAL ${ }^{1}$
}

\author{
LA CONSULTORÍA COLABORATIVA COMO UNA ESTRATEGIA DE FORMACIÓN \\ CONTINUA PARA PROFESORES QUE TRABAJAN CON ESTUDIANTES CON \\ DISCAPACIDAD INTELECTUAL
}

\begin{abstract}
COLLABORATIVE CONSULTING AS A STRATEGY OF CONTINUING EDUCATION FOR TEACHERS ACTING WITH STUDENTS WITH INTELLECTUAL DISABILITIES
\end{abstract}

Danúsia Cardoso $\mathrm{LAGO}^{2}$ Dulcéria TARTUCI ${ }^{3}$

RESUMO: A colaboração entre profissionais da educação especial e comum fomentou uma pesquisa de pós-doutorado, cujo objetivo foi analisar a Consultoria Colaborativa como estratégia pedagógica para formação continuada de professores que atuam com estudantes com deficiência intelectual. Trata-se de um estudo de abordagem qualitativa pautado nos pressupostos da pesquisa colaborativa e da Teoria Histórico Cultural. Ocorreu na Universidade Federal de Goiás - UFG e em duas escolas; participaram seis professoras da rede estadual de ensino. Os dados foram construídos nos meses de fevereiro a dezembro de 2016. Nesse recorte analisou-se uma das categorias advindas do Roteiro de entrevista, contendo a avaliação da formação. Os resultados apontaram que esse tipo de formação proporciona discussões com foco na escolarização, apresenta caminhos possíveis para uma prática docente que visa a potencialidade desses estudantes e pode se constituir como estratégia para os cursos de formação continuada.

PALAVRAS-CHAVE: Educação especial. Consultoria colaborativa. Formação de professores. Deficiência intelectual.

RESUMEN: La colaboración entre profesionales de la educación especial y común fomentó una investigación de postdoctorado, cuyo objetivo fue analizar la Consultoría Colaborativa como estrategia pedagógica para formación continua de profesores que actúan con estudiantes con deficiencia intelectual. Se trata de un estudio de abordaje cualitativo pautado en los supuestos de la investigación colaborativa y de la Teoría Histórico Cultural. Ocurrió en la Universidade Federal de Goiás - UFG y en dos escuelas; seis profesoras de la red

\footnotetext{
${ }^{1}$ Parte da pesquisa de Pós-doutorado: Consultoria Colaborativa Educacional viabilizando o Coensino entre professor regente e de apoio à inclusão escolar, desenvolvida no Programa de Pós-Graduação em Educação da Universidade Federal de Goiás, Regional Catalão, atual Universidade Federal de Catalão (UFCAT).

${ }^{2}$ Universidade Federal da Bahia (UFBA), Instituto Multidisciplinar em Saúde, Vitória da Conquista - BA Brasil. Professora Adjunta em Regime de Dedicação Exclusiva. Doutorado em Educação do Indivíduo Especial e Pós-doutorado em Educação. ORCID: https://orcid.org/0000-0002-7652-7613. E-mail: danusia.lago@ufba.br

${ }^{3}$ Universidade Federal de Catalão (UFCAT), Catalão - GO - Brasil. Professora do Programa de Pós-Graduação. Coordenadora do Curso de Letramento para Estudantes com Deficiência e do Estágio do Curso de Pedagogia e Preside a CAD (UAEE/UFG). Pós-Doutorado em Educação Especial (PPGEEs-UFSCar). ORCID: https://orcid.org/0000-0001-8340-7284. E-mail: dutartuci@gmail.com
} 
estadual de enseñanza participaron. Los datos fueron construidos en los meses de febrero a diciembre de 2016. En este recorte se analizó una de las categorías advenidas del Guía de entrevista, conteniendo la evaluación de la formación. Los resultados señalaron que este tipo de formación proporciona discusiones con enfoque en la escolarización, presenta caminos posibles para una práctica docente que tiene en cuenta la potencialidad de estos estudiantes y puede constituirse como estrategia para los cursos de formación continua.

PALABRAS CLAVE: Educación especial. Consultoría colaborativa. Formación de profesores. Deficiencia intelectual.

ABSTRACT: Collaboration between special and common education professionals stimulated a Post-doctoral research, whose goal was to analyze the Collaborative Consulting as a pedagogical strategy for continuing education of teachers acting with students with intellectual disabilities. This is about a study of a qualitative approach discussed on the assumptions of the collaborative reasearch and the Historic Cultural Theory. It ocurred at the Universidade Federal de Goiás - UFG and another two schools; six teachers of the state education network had participated. The data were constructed on the months of february to december of 2016. In that matter were anylised one of the interview script resulting categories, containing the training evaluation. The results pointed out that this kind of training provides discussions focusing on schooling, presents possible paths to a teaching practice that aims the potenciallity of those students and can be constituted as a strategy for continuing education courses.

KEYWORDS: Special education. Collaborative consulting. Training of teachers. Intellectual disability.

\section{Introdução}

Universalizar o ensino básico para estudantes com deficiência, transtornos globais do desenvolvimento e altas habilidades ou superdotação, denominados, na Política de Educação Especial na Perspectiva Inclusiva de 2008 e no Decreto 7.611/2011, como público-alvo da educação especial, constitui-se mais um desafio para a educação brasileira. Desafio esse que se ramifica para diversas áreas, entre elas, a formação continuada dos professores e profissionais da educação para atuarem com esse público. Nesse sentido, cursos e especializações que abordam as demandas que envolvem a inclusão escolar estão entre os mais solicitados pelos docentes (LAGO; TARTUCI, 2016; 2018).

A formação de professores, tanto inicial quanto continuada, vem passando por mudanças conceituais com vistas a uma prática reflexiva, e essas mudanças reverberam na formação para educação especial na perspectiva inclusiva. Estudos apontam a necessidade de cursos em consonância com as demandas do contexto escolar em articulação teoria e prática, visando a autonomia profissional dos professores ao refletirem sobre sua ação, buscando 
transformar sua prática. Os professores apontam para a necessidade de cursos de formação que considerem o contexto da escola e da sua sala de aula, bem como maior interação entre universidade e escola (PLETSCH, 2009; VIRALONGA; MENDES, 2014; CAMAROMRI, 2014; LAGO; TARTUCI, 2016; 2018; CAMPOS, 2018).

No Brasil, Capellini (2004); Mendes (2006); Braum (2012), Camaromri, 2014; Vilaronga e Mendes, 2014; Araújo e Almeida (2014); Machado e Almeida (2015); Lago e Tartuci (2016; 2018) e Campos (2018) desenvolveram ou analisaram pesquisas pautadas na colaboração entre profissionais que atuam na educação especial e comum. De maneira geral, relataram que essas pesquisas trouxeram resultados positivos para professores que participaram da formação, bem como para formadores e os estudantes com deficiência. Destacaram que a colaboração entre profissionais da educação tem ocorrido na forma do Ensino Colaborativo ou da Consultoria Colaborativa, e que ambas modalidades têm rompido com a cultura do trabalho isolado entre esses profissionais, o que tem favorecido a formação em serviço com vistas à inclusão escolar efetiva de estudantes com deficiência, resultando em uma estratégia eficaz de formação continuada, visto que são cursos que buscam uma articulação estreita com o contexto escolar.

Diante do exposto, buscou-se durante uma pesquisa de Pós-doutoramento implementar um curso de formação continuada para professores com base na colaboração como metodologia de trabalho. Este artigo, parte da pesquisa maior, teve por questão de pesquisa: A Consultoria Colaborativa pode se constituir como uma estratégia na formação de professores que atuam com estudantes com deficiência? E, como objetivo, analisar a Consultoria Colaborativa como estratégia pedagógica para formação continuada de professores que atuam com estudantes com deficiência intelectual.

O presente texto apresenta a seguir o percurso metodológico do estudo, a análise dos resultados e discussões com base nos relatos das professoras participantes sobre as contribuições da Consultoria Colaborativa.

\section{Percurso metodológico}

O presente estudo foi aprovado, por meio de um Termo de Anuência, pela Subsecretaria Regional de Educação - SRE de Catalão - Góias e pelos responsáveis do setor de Educação Especial. Em seguida o Comitê de Ética em Pesquisa da UFG aprovou o estudo sob CAEE nº 49751915.4.0000.5083. 
Trata-se de uma pesquisa colaborativa baseada nos pressupostos da Teoria Histórico Cultural, cuja metodologia de análise foi a abordagem qualitativa. É um tipo de pesquisa intrínseca à prática, sem, contudo, deixar de usar os conhecimentos científicos na busca do desenvolvimento profissional dos participantes. Nesse tipo de pesquisa os professores são encorajados a refletirem criticamente sobre sua prática docente, a refinarem suas ideias, a terem acesso aos conhecimentos acadêmicos sobre determinado assunto e atrelá-los aos conhecimentos práticos da sua vida profissional (BOGDAN; BIKLEN, 1994; IBIAPINA, 2008).

Ao todo participaram seis professoras, denominadas com o objetivo de manter sigilo sobre a identificação das mesmas, de P1 até P6; foram selecionadas a partir dos seguintes critérios: a) ter contato com aluno com deficiência; b) aceitar participar da pesquisa por meio da assinatura do Termo de Consentimento Livre e Esclarecido - TCLE. Essas professoras exerciam diferentes funções dentro da escola onde atuavam, conforme descrição no Quadro 1.

Quadro 1 - Identificação e função das professoras participantes

\begin{tabular}{|c|l|}
\hline $\begin{array}{c}\text { PROFESSORA } \\
\text { PARTICIPANTE }\end{array}$ & \multicolumn{1}{c|}{ FUNÇÃO } \\
\hline P1 & Gestão escolar (Diretora) \\
\hline P2 & Professora de Apoio à inclusão escolar \\
\hline P3 & Professora da Sala de Recurso Multiprofissional - SEM \\
\hline P4 & Gestão escolar (Coordenadora Pedagógica) \\
\hline P5 & Professora voluntária atuando em colaboração a profa. da SRM \\
\hline P6 $^{5}$ & Pesquisadora/mestranda que acompanhou e avaliou a efetividade do curso \\
\hline
\end{tabular}

Fonte: Elaborado pelas autoras.

Todas as participantes possuem formação inicial em Pedagogia com especialização na área de Educação; uma das participantes possui Mestrado em Educação e outra estava cursando o mestrado; a faixa etária variou entre 20 e 50 anos; o tempo de atuação profissional era mais de 20 anos para a maioria das professoras, e apenas duas atuavam de dois a seis anos como professoras.

Com base nos pressupostos da pesquisa colaborativa buscou-se a sistematização de alguns procedimentos em conformidade com Ibiapina (2008): as professoras participaram de uma primeira reunião na UFG visando a sensibilização das mesmas; nessa reunião elas

\footnotetext{
${ }^{4}$ Essa professora atuava na rede de ensino privado, o curso era aberto à comunidade, e como estratégia teria que realizar o ensino colaborativo com uma professora da rede estadual e dessa forma atuou colaborativamente junto a uma professora da SRM participante do estudo.

${ }^{5}$ Professora da Rede Estadual que durante o curso participou como Mestranda do Programa de Pós-Graduação em Educação, Regional Catalão, cujo objeto de sua pesquisa era o referido curso.
} 
conheceram o objetivo da pesquisa, tiraram suas dúvidas, assinaram o TCLE e responderam o questionário de identificação pessoal e profissional. Também foi realizado um diagnóstico das necessidades de formação e em seguida foram elaborados os ciclos de formação reflexiva.

No primeiro ciclo, cada professora recebeu um material de apoio impresso e encaderno, elaborado pela pesquisadora/consultora e a supervisora da pesquisa, contendo referencial teórico sobre Inclusão escolar e a política educacional brasileira, Escolarização dos alunos com deficiência intelectual: história e diretrizes políticas, Definições da deficiência intelectual ao longo dos séculos, Organização do trabalho pedagógico envolvendo estudantes com deficiência intelectual na sala de aula comum e no Atendimento Educacional Especializado, $\mathrm{O}$ ensino colaborativo ou coensino como serviço de apoio aos professores que atuam com alunos com deficiência e sobre a Consultoria Colaborativa Educacional como estratégia de formação em serviço. Todos esses temas foram discutidos e analisados ao longo do curso.

A produção de dados foi realizada em dois locais: Universidade Federal de Goiás UFG - Regional Catalão e em duas escolas da rede estadual. Os ciclos de formação reflexiva aconteceram nos meses de março a dezembro de 2016, durante dois a três dias da semana de cada mês - perfazendo um total de 17 encontros formativos na UFG. Concomitante aos ciclos de formação ocorria a Consultoria Colaborativa no contexto das duas escolas, cerca de 10 encontros em cada unidade escolar onde as participantes atuavam. Cada encontro teve uma duração média de 3 horas, distribuídos entre observações, conversas com as professoras, com os pais, realização de avaliações e reavaliações pedagógicas dos estudantes.

O foco da formação foram os professores, contudo, é preciso descrever de forma resumida como se deu essa parceria com esses estudantes. $\mathrm{O}$ primeiro contato ocorreu durante a Consultoria nas escolas: os mesmos foram avaliados em seus aspectos pedagógicos e em seguida foi proposto, individualmente, um plano contendo orientações acadêmicas e adaptações curriculares. Ao todo foram acompanhados 8 estudantes com DI do ensino fundamental I, cuja faixa etária variou de 7 a 15 anos de idade.

Nesse recorte estão descritos, analisados e discutidos os dados advindos da Categoria: As contribuições de um curso de formação continuada baseado na Consultoria Colaborativa, elaborado a partir do Roteiro de entrevista semiestruturada, aplicado ao final do curso; a análise foi desenvolvida por meio da abordagem qualitativa e os relatos estão descritos com recuo e em itálico com objetivo de demonstrar a fala da participante e não ser confundida com as citações diretas. 


\section{As contribuições de um curso de formação continuada baseado na Consultoria Colaborativa}

Países como Estados Unidos, Canadá e Itália vêm se baseado no modelo de colaboração entre professores da educação comum e da educação especial como mais uma estratégia à escolarização dos alunos com deficiência e à formação dos professores. Desde a década de 1980, pesquisadores como Pugach e Johnson já apontavam a importância de estabelecer uma parceria colaborativa entre esses profissionais. Contudo, uma proposta sistematizada ocorreu nos Estados Unidos, no ano 1993, no Estado da Lousiana, quando Friend e Cook (1990) implementaram um trabalho colaborativo junto aos professores do ensino comum que atuavam com estudantes com deficiência (MENDES, 2006; ARAÚJO; ALMEIDA, 2014).

No Brasil, os estudos realizados por Capellini (2004); Mendes (2006); Braum (2012), Araújo e Almeida (2014); Machado e Almeida (2015); Lago e Tartuci (2016/18) e Campos (2018) corroboram com a estratégia da colaboração e afirmaram a necessidade de ampliação do apoio mútuo entre os profissionais da educação, desde o compartilhamento das responsabilidades até a troca de experiências exitosas sobre a escolarização dos estudantes com deficiência.

O trabalho colaborativo efetivo requer compromisso, apoio mútuo, respeito, flexibilidade e uma partilha dos saberes. Nenhum profissional deveria considerar-se melhor que os outros. Cada profissional envolvido pode aprender e pode beneficiar-se dos saberes dos demais e, com isso, o beneficiário maior será sempre o aluno. (CAPELLINI, 2004, p. 89)

Essa colaboração pode ocorrer por meio de dois modelos: Ensino Colaborativo/Coensino ou Consultoria Colaborativa. O primeiro é baseado na atuação de dois ou mais professores na sala de aula comum com vistas a favorecer a aprendizagem dos estudantes com deficiência; geralmente ocorre entre professor/consultor especializado em educação especial e um professor da sala de aula comum que juntos elaboram estratégias de ensino diferenciadas para que esses estudantes desenvolvam suas potencialidades em termos de autonomia, socialização e de aprendizagem. O segundo modelo é formado por consultores escolares - professores de educação especial, fonoaudiólogos, terapeutas ocupacionais, fisioterapeutas, psicólogos, etc. - que têm por objetivo promover ampliação profissional aos docentes e a participação do estudante com deficiência não apenas na sala de aula comum, mas em todo contexto escolar por meio da parceria estabelecida com a comunidade escolar (MENDES, 2006; MACHADO; ALMEIDA, 2015; LAGO; TARTUCI, 2016; 2018). 
Nessa perspectiva, na formação aqui descrita foi utilizado o modelo da Consultoria Colaborativa na assistência aos participantes, tendo por base a pesquisa colaborativa, que tem o propósito de produzir conhecimento e a formação de professores em diferentes áreas. Essa assistência ocorreu durante os ciclos de formação reflexiva na UFG e in loco, nas escolas das participantes. A pesquisa colaborativa e o processo da consultoria colaborativa segue algumas etapas: encaminhamento, discussões iniciais com os professores visando o estabelecimento de uma parceria colaborativa, observação da sala de aula desses professores, possíveis reuniões com pais/responsáveis dos estudantes com deficiência, avaliação pedagógica, encaminhamentos e um plano de intervenção que deve ser monitorado durante todo o processo. Ou seja, é preciso que o consultor/pesquisador obtenha o máximo de informações possíveis sobre cada caso (KAMPWIRTH, 2003; IBIAPINA, 2008).

Os resultados apontaram várias contribuições da Consultoria Colaborativa enquanto estratégia de formação continuada aliada à pesquisa colaborativa. O Quadro 2 apresenta as Subcategorias da Categoria objeto deste artigo.

Quadro 2 - Categoria e subcategorias analisadas

\begin{tabular}{|c|c|}
\hline $\begin{array}{l}\text { CATEGORIA } \\
\text { Consultoria Col }\end{array}$ & $\begin{array}{l}\text { As contribuições de um curso de formação continuada baseado na } \\
\text { orativa }\end{array}$ \\
\hline & Principais mudanças na prática docente após participar desse curso \\
\hline & A articulação entre Universidade/Escola \\
\hline Subcategorias & $\begin{array}{l}\text { Os conhecimentos e habilidades adquiridos durante curso e relação com a } \\
\text { prática pedagógica na escola }\end{array}$ \\
\hline & Colaboração entre os professores \\
\hline & Consultoria Colaborativa como estratégia de formação em serviço \\
\hline
\end{tabular}

Fonte: Lago e Tartuci (2016/2018) com base na transcrição das entrevistas

\section{Principais mudanças na prática docente após participar desse curso}

Além da ampliação dos conhecimentos, essa formação proporcionou mudanças na prática docente da sala de aula e o entendimento de que o estudante com DI é capaz de aprender. Nesse sentido, Campos (2018, p. 128) relatou em sua pesquisa que a Consultoria Colaborativa tem como foco a escolarização do estudante com deficiência e não a deficiência em si. Para essa autora, essa proposta difere do modelo médico-pedagógico ao impulsionar a aprendizagem do estudante no sentido acadêmico e humano, pois de acordo com "[...] a Teoria Histórico-Cultural, o professor deve proporcionar a todos os alunos os conhecimentos sistematizados e construídos historicamente pela humanidade.”, pressupostos contidos nas formações de professores com base na colaboração. 
[...] ]avaliar o nível de desenvolvimento dos alunos nos deu uma posição real, do que o aluno realmente é capaz de aprender, de desenvolver enquanto estudante e enquanto ser humano com potencial foi uma das primeiras mudanças [...] essa formação nos mostrou que é possível ampliar nossos conhecimentos teóricos sobre a deficiência e colocar esses conhecimentos em prática. [...] o suporte da formadora dentro da escola foi contagiante! (P1 - Professora/ Diretora escolar)

O relato da P1 corrobora com Pletsch (2009, p. 145), quando esta sinalizou que o professor deve ser formado na perspectiva de "[...] mobilizar seus conhecimentos, articulando-os com suas competências mediante ação e reflexão teórico prática.”

\section{A articulação entre Universidade/Escola}

Outro destaque apontado pelas participantes foi a parceria entre uma pesquisadora/professora de Universidade com a escola. Campos (2018) enfatizou em seu estudo, cujo objetivo foi avaliar este curso de formação, que

[...] a articulação entre universidade e escola possibilitou espaços para reflexões coletivas e aprimoramento pessoal e profissional das participantes, posto que, a visão acerca da própria prática, dessas profissionais, foi sendo ressignificada durante todo o processo de formação e, contribuiu para o desenvolvimento profissional com caráter emancipatório (CAMPOS, 2018, p. 112).

De acordo com Mendes (2006), Caramori (2014) e Araújo e Almeida (2014), a intenção desse tipo de parceria é contribuir para uma reflexão crítica sobre práticas educacionais articuladas à formação no contexto escolar, favorecendo a resolução de problemas reais com repercussão positiva na ampliação do aprendizado dos estudantes com deficiência e na atuação direta dos professores junto a esses estudantes. A oportunidade de participar da formação teórica nos encontros na Universidade, aliado ao apoio da consultora na escola, foi fundamental na ampliação dos conhecimentos, conforme relatado pela P2.

Para mim foi um curso diferente dos demais que fiz até agora, pois ao mesmo tempo que ia para a universidade adquirir os conhecimentos teóricos, a professora da Universidade vinha para nossa escola conhecer os nossos alunos e nos ajudar a direcionar o trabalho com os alunos com DI; [...] (P2 - Professora de Apoio sala de aula comum).

As participantes, de maneira geral, relataram que a consultoria articulada à experiência da consultora/formadora em educação especial fomentou a busca de outras possibilidades de atuação junto aos estudantes com deficiência intelectual, assim como a parceria 
universidade/escola ampliou as perspectivas de uma formação colaborativa, pautada no diálogo em articulação ao cotidiano da escola.

\section{Os conhecimentos e habilidades adquiridos durante curso e relação com a prática pedagógica na escola}

Para as participantes, a ampliação dos conhecimentos sobre a deficiência intelectual em seus aspectos históricos, biopsicossociais e acadêmicos tiveram uma relação intrínseca com a prática da sala de aula. A partir da discussão e reflexão desses aspectos puderam implementar mudanças pedagógicas na escola, pois esses conhecimentos passaram a fundamentar suas práticas docentes.

Com o aumento de alunos com deficiência nas escolas regulares em sala comum, muitos professores não se sentem preparados para atender academicamente as especificidades que esses alunos apresentam, pois para muitos falta informação sobre as variadas deficiências e síndromes: falta também capacitação profissional, o que pode acarretar entraves para o desenvolvimento de um trabalho acadêmico de qualidade na escola que se diz para todos. (SILVA; CARNEIRO, 2016, p. 938)

Relataram que passaram a atuar com vistas à eliminação das barreiras e dificuldades impostas pela deficiência e voltaram seus olhares na busca de caminhos possíveis para a escolarização desses estudantes, tendo como foco o potencial de cada um e não sua deficiência.

Tiveram muita relação, principalmente quando estudamos sobre deficiência intelectual: o contexto histórico, as características, as possibilidades de trabalhar com eles[...] até o jeito de tratar o aluno, de falar com ele. [...]Os instrumentos de avaliação que tivemos acesso no curso foram colocados em prática na avaliação dos mesmos, as diferentes estratégias de ensino [...]. Tudo era relacionado a nossa prática dentro da escola. Os temas mais teóricos foram a base para pensarmos nossas atividades com esses estudantes [...] mudamos o foco que era mais voltado para deficiência e passamos a olhar o potencial deles ( $\mathrm{P} 3$ - Professora da SRM).

Para Braum (2012) e Campos (2018), a possibilidade de um trabalho pedagógico que visa os aspectos históricos, biopsicossociais e acadêmicos do estudante é o ponto de partida para reflexão do processo de ensino e aprendizagem envolvendo estudantes com deficiência intelectual. A complexidade reside na constatação que as mudanças não ocorreram porque o foco era a deficiência ou mesmo porque não tinham conhecimento de como implementar determinadas ações. 


\title{
A Colaboração entre os professores e demais profissionais da escola
}

Conforme Mendes (2006), Pletsch (2009); Araújo e Almeida (2014) e Tartuci; Vinhal e Dias (2019), a formação baseada na colaboração entre os profissionais aborda os conhecimentos teóricos, conduz sua prática pedagógica nos momentos da consultoria, além de fomentar a cultura da colaboração no ambiente escolar. É uma formação que provoca discussões e reflexões sobre as práticas pedagógicas visando a aprendizagem de todos os alunos.

\begin{abstract}
Depois que a gente estuda o que que é colaboração, a perspectiva da gente enquanto profissional muda também, porque a gente vem de uma cultura que cada profissional cuida do seu quadrado, do seu serviço, da sua sala, trabalho isolado [...]. Eu achava que nem era possível isso, nem tinha pensado nessa perspectiva [...]. Hoje percebo que seria a solução para melhorar a educação porque a facilidade de um professor pode ser a dificuldade do outro, e assim por diante; [...]. Essa rede de colaboração faz todo sentido, [...] essa colaboração tem que ser com todos os profissionais da escola: professor regente, professor de apoio, do AEE e da coordenação também (P4 - Coordenadora Pedagógica).
\end{abstract}

Corroborando com o relato da P5, a pesquisa realizada por Tartuci, Vinhal e Dias (2019, p. 175) destacou que a interação entre os professores regentes de referência e os professores de apoio à inclusão em geral ocorre de forma isolada, sem que haja um planejamento conjunto ou mesmo um diálogo, condição distinta das estratégias adotadas pelo ensino colaborativo, que "é uma estratégia eficaz junto aos [...] a qual exige a participação, compromisso, apoio mútuo, flexibilidade, partilha de saberes dos profissionais envolvidos, [...]." A prática da colaboração no espaço da escola exige mudanças de toda equipe escolar, desde as mudanças de concepções sobre o trabalho em equipe ao favorecimento de práticas democráticas que buscam o compartilhamento de conhecimentos e experiências.

Este tipo de consultoria requer trabalho intensivo e treinamento para trabalhar em equipe; tal treinamento inclui a aprendizagem de habilidades sociais e de princípios éticos, como respeito às diferenças culturais. Este trabalho também requer a revisão de certas crenças e conceitos com relação ao ensino comum e especial, levando a uma superação do binômio ensino comum/especial (ARAÚJO; ALMEIDA, 2014).

Com a colaboração, as habilidades individuais dos profissionais da educação são articuladas na resolução dos problemas e demandas da escola, pois conforme pontua El Kadri, Molinari e Ramos (2019, p. 2098) “[...] a formação profissional não deve ser estritamente técnica; ela deve ter como objetivo, sobretudo, preparar cidadãos que valorizem práticas 
democráticas, dentre as quais figura a colaboração". A partir da perspectiva colaborativa é possível estabelecer vários tipos de parceria dentro da escola e dentro da sala de aula, como no exemplo apontado no relato da P5.

Quando eu iniciei o trabalho, eu não tinha experiência com estudantes com deficiência intelectual, com a colaboração e trabalhava isolada! Até o momento só tinha participado de formação técnica [...]. A experiência da formadora e os exemplos discutidos com a equipe me auxiliou muito. [...] As tarefas infantilizadas, repetitivas, sem novidades, fora do contexto foram substituídas por atividades próximas ao conteúdo da sala. A professora regente passou a me entregar o plano de aula com os conteúdos para eu adaptar [...] a formadora convidou a professora regente para se juntar a nós e democraticamente elaborávamos mais estratégias." (P5 - Professora voluntária atuando em colaboração na SRM).

Durante a Consultoria Colaborativa buscou-se a colaboração entre o professor regente, o de apoio e o da SMR, pois geralmente esses três professores acompanham o mesmo estudante e não compartilham os saberes, as experiências, nem entre eles e nem com a comunidade.

\section{Consultoria Colaborativa como estratégia de formação em serviço}

De acordo com Vilaronga e Mendes (2014); Araújo e Almeida (2014), a Consultoria Colaborativa enquanto estratégia de formação em serviço estabelece sistemas de colaboração e de cooperação ao criar e fortalecer uma rede de apoio aos profissionais da escola.

Portanto, a proposta de consultoria colaborativa consiste em levar o trabalho dos especialistas para dentro da escola, assim esse modelo propõe contribuir de forma salutar para, a partir de alguns problemas vivenciados pelo professor na escola, seja viável a construção de ações que potencializem o seu trabalho e atenda às necessidades do seu alunado. (MACHADO; ALMEIDA, 2015, p. 224)

Nos ciclos de formação reflexiva discutiu-se as nuances que envolvem o acesso e a permanência dos estudantes com deficiência, não apenas pela ampliação das matrículas nos últimos 15 anos, mas principalmente pela falta de recursos humanos e materiais que poderiam colaborar efetivamente com uma educação de qualidade. Temas como a inclusão escolar e a política educacional brasileira; os aspectos históricos e diretrizes políticas que envolveram/envolvem a escolarização do estudante com deficiência intelectual; as formas de identificação dessa deficiência, incluindo a definição do termo, a inclusão escolar e a organização do trabalho pedagógico envolvendo esses estudante na sala de aula comum e na SRM, a importância da colaboração/parceria entre os profissionais da escola, da educação 
especial e da parceria universidade/escola. Essas discussões eram seguidas de reflexões e análises acerca da realidade vivenciada pelos participantes com base nos casos dos estudantes com deficiência intelectual matriculados em suas escolas.

A formação com a consultoria colaborativa mostrou a melhor a forma de trabalhar; saímos daquela burocracia do papel e ficha e fomos para o real; [...] muitos professores não fazem o que deveria ser feito, não é porque não querem, é por desconhecimento do que deveria ser feito. As vezes a pessoa é super capaz, mais ainda não tem os conhecimentos necessários para trabalhar com o aluno com deficiência e essa formação trabalhou nossos problemas reais. [...] ( $\mathrm{P} 4$ - Coordenadora Pedagógica)

No desenvolvimento da formação foi discutido junto aos professores e comunidade a participação do estudante com deficiência não apenas na sala de aula comum, mas em todo âmbito da escola. Nesses momentos também ocorriam o levantamento das demandas do contexto escolar e o acompanhamento das implementações das mudanças pedagógicas sugeridas durante os ciclos de formação.

Foi uma formação que nos motivou e motivou os alunos com deficiência intelectual. Eles adoravam o dia em que a pesquisadora vinha à escola. [...] A maior contribuição que eu aponto foi abrir nossos olhos sobre o fato do aluno com deficiência ser aluno da escola e não apenas daquela professora, as responsabilidades foram divididas. Nunca tinha passado por um curso assim! Ele te dá nos mínimos detalhes, ele te explica; você tem a parte teórica que é como se fosse uma prática, [...] é como se eu estivesse em uma sala de aula e que isso tivesse acontecendo; eu vivenciava a situação. (P3 Professora da SRM)

Para Machado e Almeida (2015); Lago e Tartuci (2016; 2018), cabe ao consultor em educação especial oportunizar ampliação do desenvolvimento profissional dos docentes pautado nas demandas do ambiente escolar, auxiliando-os na construção de estratégias pedagógicas que favoreçam as potencialidades dos estudantes com deficiência. Nesse sentido, Almeida (2016, p. 55) argumentou que “[...]. É necessário que a escola se apoie no que a criança é, e não no que lhe falta, [...] adotando uma pedagogia ancorada em aspectos positivos $[\ldots]^{\prime}$.

A formação colaborativa fomenta discussões, amplia informações sobre o tema, apresenta caminhos possíveis para uma prática docente diferenciada e significativa para todos os estudantes, sem, contudo, deixar de fazer uma reflexão crítica sobre as melhores condições de escolarização e de trabalho para os profissionais da escola que atuam ou atuarão com esses estudantes. 
Eu cresci muito profissionalmente com esse acompanhamento [...] porque como eu não tinha experiência como professora de apoio e o curso foi norteando, dando segurança, [... ] durante a consultoria tínhamos o retorno das ações que estavam sendo implementada e a consultora apontava outros caminhos que a gente que está ali envolvida no processo diário com o aluno passa despercebido e não consegue enxergar e vê daquela maneira (P2 Professora de Apoio sala de aula comum).

Durante a pesquisa, as participantes tiveram acesso a vários instrumentos de avaliação pedagógica propostos por Vilaronga e Mendes (2014), Lago e Tartuci (2016; 2018). Outros instrumentos, como diários de campo e roteiro de avaliações pedagógicas para os alunos com deficiência intelectual, foram elaborados em conjunto com as professoras participantes. A cada novo encontro eram abordadas questões norteadoras referentes ao assunto/conteúdo apresentado no dia, bem como as questões que envolveriam a prática da sala de aula e da Consultoria realizada nas escolas.

As contribuições foram muitas! [...] foi uma formação continuada; [...] a cada encontro foi discutido assuntos pertinentes a educação inclusiva; tanto a parte legal quanto a parte pedagógica, a parte de documentação e até coisas que a gente não sabia, aqueles testes eu nunca tinha visto...então, foi totalmente diferente. As discussões, as trocas de experiências e até a motivação que a gente teve foi diferente. Nossa, eu achei excepcional! [...] fazer esse trabalho diretamente na escola nos deu uma posição real, do que realmente o aluno é capaz de fazer, de desenvolver [...] (P1 - Professora/ Diretora escolar).

Para Campos (2018, p.104), “[...] A formação continuada pode ser uma importante forma para aproximar professores dos pressupostos e da prática da Inclusão escolar e, dessa forma, contribuir para que a escola cumpra de fato seu papel de socialização do saber”. Em uma formação na perspectiva colaborativa, os participantes tornam-se coautores no processo de geração de conhecimento. Consultora e participantes buscam a teoria não como produto isolado, mas como processo articulado com a prática educacional.

A partir das teorias estudadas, das discussões e das reflexões propostas pela professora formadora acerca da escolarização dos alunos com deficiência intelectual e da importância da colaboração na escola, verifiquei mudanças nas posturas e nas ações das participantes que se refletiram na atuação dentro das escolas que visitei. [...] Todas as participantes consideraram esse curso, uma verdadeira formação continuada, da qual ainda não tinham participado (P6 -Mestranda que participou do curso enquanto pesquisadora/avaliadora).

As concepções das professoras participantes sobre a Consultoria Colaborativa enquanto estratégia de formação em serviço se pautaram desde a importância da parceria universidade/escola até a constatação de que o trabalho em colaboração favorece a 
escolarização dos estudantes com deficiência e amplia os conhecimentos da equipe escolar sobre inclusão escolar.

\section{Considerações finais}

Ao final dessa pesquisa verificou-se que é preciso repensar a formação inicial e continuada dos professores com vistas à educação inclusiva. As participantes foram unânimes em relatar que o formato e metodologia de um curso baseado na colaboração atendem de maneira mais efetiva as demandas advindas da inclusão escolar, pois fomentam a participação do professor que atua diretamente com o estudante com deficiência e toda equipe gestora e administrativa da escola.

Para atender às demandas da educação inclusiva, os profissionais da escola necessitam adquirir novas competências, e esse tipo de formação instiga um movimento de reconstrução tanto da formação inicial quanto continuada, pois fortalece a autonomia profissional numa perspectiva crítica e emancipatória do papel social da profissão docente.

A proposta de formação com base na Consultoria Colaborativa não tem a pretensão de se tornar a única via de formação docente ou de apresentar "receitas" de como o professor da sala de aula comum, o professor de apoio à inclusão escolar, o professor da SRM ou mesmo o gestor escolar devem atuar com o estudante com deficiência ao contrário, a intenção dessa estratégia de formação é a de dialogar, contextualizar a realidade educacional vivenciada pelos professores por meio da interação e da colaboração entre o(a) consultor(a) em Educação Especial e os profissionais da escola.

AGRADECIMENTOS: À Coordenação de Aperfeiçoamento de Pessoal de Nível Superior CAPES, às colaboradas dessa pesquisa: Profa. Ms. Daniela Maria Ferreira Campos, Profa. Dra. Maria Marta Lopes Flores e às professoras participantes da pesquisa.

\section{REFERÊNCIAS}

\section{ALMEIDA, R. V. de M. Escolarização dos alunos com deficiência intelectual: a} construção de conhecimento e letramento. Orientadora: Dulcéria Tartuci. 2016 240f. Dissertação. (Mestrado em Educação). Universidade Federal de Goiás - Regional Catalão. 2016. Disponível em: http://repositorio.bc.ufg.br/tede/handle/tede/6197. Acesso em: 27 fev. 2020. 
ARAÚJO, S. L. S.; ALMEIDA, M. A. Contribuições da consultoria colaborativa para a inclusão de pessoas com deficiência intelectual. Revista Educação Especial, Santa Maria, v. 27, n. 49, p. 341-352, maio/ago. 2014. ISSN 1984-686X. Disponível em:

https://periodicos.ufsm.br/educacaoespecial/article/view/8639. Acesso em: 03 jan. 2020.

BOGDAN, R.; BIKLEN, S. Investigação qualitativa em educação: uma introdução à teoria e aos métodos. Porto, Porto Editora, 1994.

BRAUM, P. Uma intervenção colaborativa sobre os processos de ensino e aprendizagem do aluno com deficiência intelectual. Orientadora: Leila Regina d'Oliveira de Paula Nunes. Tese. 2012. 324 f. Universidade do estado do Rio de Janeiro (UERG). Rio de Janeiro. 2012. Disponível em: http://www.bdtd.uerj.br/tde_busca/arquivo.php?codArquivo=5308. Acesso em: 21 jan. 2020.

CAMPOS, D. M F. Formação continuada na perspectiva da Consultoria Colaborativa: contribuições no contexto da inclusão escolar. Orientadora: Maria Marta Lopes Flores. 2018. 171f. Dissertação (Mestrado em Educação) - Universidade Federal de Goiás, UFG, Catalão, 2018. Disponível em: http://repositorio.bc.ufg.br/tede/handle/tede/8462. Acesso em: 10 dez. 2019.

CAPELlini, V. L. M. F. Avaliação das Possibilidades do Coensino no processo de Inclusão Escolar do Aluno com Deficiência Mental. 2004. 302 f. Tese (Doutorado em Educação Especial) - Universidade Federal de São Carlos, São Carlos, 2004.

CARAMORI, P. M. Formação em serviço de professores comuns e especializados e suas implicações na prática: uma experiência de consultoria colaborativa. Revista IberoAmericana de Estudos em Educação, v. 11, n. esp. 2, p. 1034-1047, 2016. E-ISSN: 19825587. Disponível em: https://periodicos.fclar.unesp.br/iberoamericana/article/view/8941. Acesso em: 27 mar. 2020.

DAMÁZIO, M. F. M. Metodologia do serviço do atendimento educacional especializado em uma perspectiva inclusiva na escola regular. Revista on line de Política e Gestão Educacional, v. 22, n. esp. 2, p. 840-855, dez. 2018. ISSN 1519-9029. Disponível em: https://periodicos.fclar.unesp.br/rpge/article/view/11916. Acesso em: 27 fev. 2020.

EL KADRI, M. S.; MOLINARI, A. C.; RAMOS, S. M. Pedagogia deliberativa, linguagem e poder: emancipação e transformação social na educação pelo viés da teoria crítica. Revista Ibero-Americana de Estudos em Educação, Araraquara, v. 14, n. esp. 4, p. 2088-2103, dez. 2019. E-ISSN: 1982-5587. Disponível em:

https://periodicos.fclar.unesp.br/iberoamericana/article/view/12936. Acesso em: 27 fev. 2020.

FRIEND, M.; COOK, L. Collaboration as a predictor for success in school reform. Journal of Educational and Psychological Consultation. New York, v. 1, n. 1, p. 69-86, 1990.

GIROTO, C. R. M.; POKER, R. B.; VITTA, F. C. F. 10 anos da Política Nacional de Educação Especial na Perspectiva da Educação Inclusiva em debate: trajetória, limites e desafios. Revista on line de Política e Gestão Educacional, v. 22, n. esp. 2, p. 711-715, dez. 2018. ISSN 1519-9029. Disponível em:

https://periodicos.fclar.unesp.br/rpge/article/view/11968. Acesso em: 27 fev. 2020. 
IBIAPINA, I. M. L. M. Pesquisa colaborativa: investigação, formação e produção de conhecimentos. Brasília: Líber Livro, 2008.

KAMPWIRTH, T. J. Collaborative consultation in the schools: effective practices for students with learning and behavior problems. Chapter 1: Overview of School - Based Consultation. New Jersey: Merril Prentice Hall, 2003. p. 1-39.

\section{LAGO, D. C., TARTUCI, D. Consultoria Colaborativa Educacional viabilizando o} Coensino entre professor regente e de apoio à inclusão escolar. Projeto/relatório de estágio pós-doutoral desenvolvido no Programa de Pós-Graduação em Educação da Universidade Federal de Goiás, Regional Catalão. Goiás, 2016-2018.

MACHADO, A. C.; ALMEIDA, M. A. Efeitos de uma Proposta de Consultoria Colaborativa na Perspectiva dos Professores. Revista Meta: Avaliação. v. 6, n. 18, p. 222-239, 2014. ISSN 2175-2753. Disponível em:

http://revistas.cesgranrio.org.br/index.php/metaavaliacao/article/view/160. Acesso em: 05 jan. 2020.

MANTOAN, M. T. E.; BAPTISTA, M. I. S. D. Inovar para fazer acontecer: como estamos fortalecendo redes de apoio à educação inclusiva. Revista on line de Política e Gestão Educacional, v. 22, n. esp. 2, p. 763-777, dez. 2018. ISSN 1519-9029. Disponível em: https://periodicos.fclar.unesp.br/rpge/article/view/11911. Acesso em: 27 mar. 2020.

MENDES, E. G. Colaboração entre ensino regular e especial: o caminho do desenvolvimento pessoal para a inclusão escolar. In: MANZINI, E. J. Inclusão e acessibilidade, Marília: ABPEE, 2006. p. 29-41.

PLETSCH, M. D. A formação de professores para a educação inclusiva: legislação, diretrizes políticas e resultados de pesquisas. Educ. rev., Curitiba, n. 33, p. 143-156, 2009. Disponível em: http://www.scielo.br/pdf/er/n33/10.pdf. Acesso em: 05 jan. 2020.

SILVA, S. S. da.;, CARNEIRO, R. U. C. Inclusão escolar de alunos público-alvo da educação especial: como se dá o trabalho pedagógico do professor no ensino fundamental I?. Revista Ibero-Americana de Estudos em Educação, v. 11, n. esp. 2, p.935-955, 2016. EISSN: 1982-5587. Disponível em: https://dx.doi.org/10.21723/riaee.v11.esp2.p935-955. Acesso em: 27 fev. 2020.

TARTUCI, D.; VINHAL, J. M.; DIAS, R. M. P. A atuação do professor de apoio à inclusão e do professor regente de referência de classe comum e o ensino colaborativo. In: Pesquisas, Reflexões e Experiências - Desafios e Perspectivas na Educação apresentadas no V SPPGI. 1. ed. Jundiaí, Brasil.: Paco Editorial, v. I, p. 1-13, 2019.

VILARONGA, C. A. R., MENDES, E. G. Ensino colaborativo para o apoio à inclusão escolar: práticas colaborativas entre os professores. Revista Brasileira de Educação, v. 95, n. 239, p. 139-151, 2014. Disponível em:

http://www.scielo.br/scielo.php?script=sci_abstract\&pid=S2176-

66812014000100008\&lng=pt\&nrm=iso\&tlng=pt. Acesso em: 27 fev. 2020. 


\section{Como referenciar este artigo}

LAGO, Danúsia Cardoso; TARTUCI, Dulcéria. Consultoria Colaborativa como estratégia de formação continuada para professores que atuam com estudantes com deficiência intelectual. Revista Ibero-Americana de Estudos em Educação, Araraquara, v. 15, n. esp. 1, p. 983999, maio 2020. e-ISSN: 1982-5587. DOI: https://doi.org/10.21723/riaee.v15iesp.1.13512

Submetido em: 11/10/2019

Revisões requeridas: 20/11/2019

Aprovado em: 28/12/2019

Publicado em: 30/04/2020 